\title{
HYPOTACTIC STRUCTURE IN ENGLISH
}

\author{
Dessy Kurniasy \\ IAIN Langsa \\ dessyari09@yahoo.co.id
}

\section{ABSTRACT}

This present study focuses on the study of a hypotactic structure in English. It is concerned with clause complex which is comprised of two or more clauses logically connected. The relation between clauses can be interpreted in terms of 'logical' semantic relations and system of interdependency relation parataxis and hypotaxis. The method used in this study was qualitative approach in which the data were taken from some linguistic books. The finding shows that the concept of hypotactic structure in English is divided into two types: expansion and projection. There are three kinds of expanding a clause i.e. elaboration $(=)$, extension $(+)$ and enhancement $(x)$, and two kinds of projection i.e. locution (") and idea ('). Elaboration shows that the meaning of the secondary clause is equal to the primary one, but the secondary clause does not introduce a new element into the picture but rather provides a further characterization of one that is already there. Extension is a clause that extends the meaning of another by adding something new to it. Meanwhile, enhancement shows the meaning of another clause by qualifying it with adverbial clause in traditional grammar. Furthermore, the three clauses can be finite or non-finite. Locution, on the other hand, is a projection with verbal process, in which the clause containing the sayer and the reporting verb is the dominant clause and the reported element is the dependent clause. Thus, idea is a projection with mental process that is used to report ideas, beliefs, fears and speculations. The combination of mental process with a dependent 'reporting' clause is the nominal ways of representing what people say, think and believe

\section{Keywords}

Hypotactic structure, parataxis, hypotaxis, expansion, projection

\section{INTRODUCTION}

A clause complex is comprised of two or more clauses logically connected, or put another way (Gerot and Wignell, 1994). In the same way, a sentence can be interpreted as a clause complex in which a head clause is combined together with other clauses that modify it however there is the same kind of relationship between sentence and clause and there is between 
group and word. It means that the sentence has evolved b expansion outwards from the clause.

The relations between clauses can be interpreted in terms of 'logical' semantic relation that makes up the logic of natural language. Therefore, there are two systemic dimensions to make up the systems for joining clauses in English. Those relations are combined with system of interdependence or 'tactic' system - parataxis and hypotaxis, which is general to all complex, word, group, phrase and clause alike. The hypotaxis is used to refer to the relationships in which one clause is dependent to another. The other is the logico-semantic system of expansion and projection, which is specifically an inter-clausal relation.

\section{LITERATURE REVIEW}

\section{Metafunction of language}

Systemic Functional Grammar relates grammatical categories to the communicative functions which they serve. Functional Grammar views language as a resource for making meaning (Halliday, 1994). These functions are to operate all different level of organization in the language and may be identified in terms of the constituent parts which go to form larger units. It is sociological orientation the way in which language is used for different purpose and in different situation, has shaped its own structure. It tries to describe language in use and to focus on texts and their contexts. They are concerned not only with the structures but also with how those structures construct meaning.

According to Halliday, in metafunctions of language, language is organized around a small number of functional components which correspond to the purposes which underlie all language uses, and all these 
functions have a systemic relationship with the lexicogrammar of the language.

Thus, in Functional Grammar, a language is interpreted as a system of meanings followed by forms through which the meaning can be realized.functional grammar is arranged to explain how the language is used by applying the functional components call Metafunctions, in which all languages are organized around three kinds of meaning; the ideational function (to understand the environment), the interpersonal function (to have an exchange in communication) and the textual function (to explain how language is used).

\subsection{Ideational Function}

The ideational function concerns the representation of the world. This function is used to organize, understand and express our perceptions of the world and of our own consciousness. At the level of the clause, this is conveyed by the process the participants involved in the process and associated with circumstances if there is any. The ideational function may consist of two types of subfunctions: the experiential and the logical function.

\subsubsection{Experential function}

The experiential function is largely concerned with content or ideas. Halliday states that experiential meaning tends to construct experience as interrelated parts of a whole. At clause rank, for example, it construes the world as going on consisting of a nuclear process and participant; additional participants and circumstances. The nominal group in the experiential meaning is a constituent structure, with modifiers playing a number of 
different roles with respect to the thing - Deitic, Numerative, Ephithet, Classifier and Qualifier.

\subsubsection{Logical function}

The logical function is concerned with the relationship between ideas. It is realized as another kind of particulate structure. Systemically, the logical function comprises recursive systems - such as Tense, Projection and Agency - which tend to be associated across languages with experiential meaning. Furthermore, the nominal group in the logical meaning is considered as a word complex and with modifiers as regressive dependents.

\subsection{Interpersonal Function}

Interpersonal function is concerned with the relationships set up between the speaker and his audience, between the speaker and his message and concerned with clauses as exchanges. This function is used to enable us to participate in communicative act with other people, by taking the roles and to express and understand feelings, attitudes and judgments. Therefore, the linguistic phenomena which would be dealt with metafunctions are mood and modality.

\subsection{Textual Function}

Textual function is concerned with the way the message is structured; at the level of the clause which includes thematic structure, which have theme and rheme as its elements, and information structure; beyond the clause it includes the phenomenon of cohesion. Textual function is used to relate what is said or written to the real world and to other linguistic event, this involves the use of language to organize the text itself. The textual 
function is about the verbal world, especially the flow of information in a text, and is concerned with clauses as messages. The theme is the point of departure for the message. It is the element the speaker selects for grounding what he/ she is going to say.

\section{RESEARCH METHOD}

This study used a descriptive qualitative design, as this study intended to describe the hypotactic structure in logico-semantic relations. Exclusively, this study discussed about the types of the clause function and decided the logical function in hypotactic structure. Thus, the primary data were collected by applying documentary technique which was taken from some linguistics books to support this analysis.

In analyzing the data, the writer identified the types of hypotactic structure based on the theory proposed by Halliday. Then she classified the elements into two types of hypotaxis, that is, expansion and projection. The last, she described the data obtained by using the percentage of each hypotaxis.

\section{FINDING AND DISCUSSION}

Hypotaxis is a logical interdependence between clauses where the interdependent are of unequal status. In hypotactically related clauses, the primary one is dominant and the secondary one is dependent (Halliday and Ruqaiya, 1976). Etimologically, hypotaxis derives from the Greek: bypo meaning 'below' plus taxis means 'arrangement'; hence, 'arrangement below'. The rationale for this term is that one clause is attached to the other but with a lower status. Therefore, a more usual for this is dependent clause to label a clause which is bound to another I a hypotactic relationship. The dominant clause refers to the bound one. 
Conventionally, hypotactic relations are labeled using the Greek alphabet symbol: $\alpha$ - Alpha; $\beta$ - Beta; $\gamma$ - Gamma; $\varepsilon$ - epsilon etc. from the symbolic perspective, $\alpha$ - Alpha marks the dominant clause; however, it is important to note that it is possible for the position of the secondary clause of a hypotactic structure to precede the primary clause. Thus, the $\alpha-$ Alpha does not necessarily come first in the clause complex, that is, ' $\beta-\alpha$ ' may be correct.

\section{Expansion}

The logico-semantic relations which are varied represent the way the speaker or writer sees the connections to e made between one clause and another, in its multiple function as process, exchange and message, and this may enter into construction with another clause which is an expansion of it. Expansion is one of the logico-semantic relations by which one clause expands the meaning of another in some ways (Downing \& Locke, 1992); thus, the two together forming a clause complex. Essentially, there are three types of expanding a clause: elaboration, extension and enbancement.

\subsection{Elaboration}

Elaboration clauses are clauses which clarify or comment on a primary clause (Downing \& Locke, 1992). Elaboration shows that the meaning of the secondary clause is equal to the primary one. However, the secondary clause does not introduce a new element into the picture but rather provides a further characterization of one that is already there, restating it, clarifying it, refining it, or adding a descriptive attributive or comment.

Hypotaxis combining with elaboration give non-defining relative clauses which add further information to the whole previous clause or may 
be just some of it - one or more of its constituents. The clauses can be either finite or non-finite with the primary clause and several conjunctive expressions like which, who, whose, when, where, or whom can be used to connect the clauses. Elaboration in hypotactic structure is shown through the sign ' $=$ '. With regard to meaning and expression, non-restrictive relative clauses differ from the restrictive one. The non-restrictive or non-defining relative clauses do not define subsets, as does the restrictive or defining type. Their function is to add a further specification of something that is already presented as specific. For example:

a. This is my expensive book, which was given by my father

b. We met his wife, which stay in Kisaran

$(\alpha)$

c. My brother has a good career, who works in famous company

$(\alpha)$

$\mathrm{d}$. This is the best seller book, where could only found I several bookstore

$(\alpha)$

The italic sentences are non-defining relative clause, and they do not pinpoint their antecedents. However, their function is rather to provide additional information about the antecedent. Their function is not to restrict the scope of reference of a head, but almost parenthetically, to comment further. With regard to expression non-defining relative clause is clearly signaled both in speech and in writing. Furthermore, in written English, it (non-defining) forms a separate tone group which is linked to the main clause by tone concord; in other words, they are spoken on the same tone. A non-defining clause is marked off by punctuation, usually commas but 
sometimes a dash, especially when the antecedent is a whole clause which is shown on the example above.

The non-finite verb forms -ing, to-infinitive and -en participle are used non-restrictively to express the same meanings as the finite forms, and agin the domain may be one nominal group or some larger segment of the primary clause, up to the whole clause, for example:

a. My father sits by the window, wearing black suits

b. To make the audience feel comfortable, the clown shows a funny

attractive

c. The district lost, burnt by a big fire

The above sentences consist of non-finite clauses and they have less specific meaning. Both the domain of the dependent clause and its semantic relationship to its domain are left relatively inexplicit. There is no $\mathrm{WH}-$ form as there is with the finites.

\subsection{Extension}

In extension, one clause extends the meaning of another by adding something new to it. The combination of extension with hypotaxis also embraces addition, replacement and alternation, but with the extending clause dependent. As well as elaboration clause the extending clause can be finite or non-finite. The extension clause is marked by a ' +' sign. The finite form of clauses are introduced by the conjunctions whereas, while, except that, but for the fact that. For example:

a. The man do nothing, while his mother work hard all day long 
(a) $\quad+$

b. The children have not found yet, whereas her mother felt worry so much
$+$

The conjunctions whereas and while introduce finite dependent clauses which contrast in some way with the primary clause, especially when there is also some point of similarity between the two sentences above, whereas is more formal than while. However, there is no finite form for replacement, but for subtraction the finite clause is introduced by except that, but that and but for the fact that. For example:

a. He kept on pretty well, except that he had a babit of falling off side a way

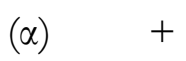

b. It would have been a disaster, but for the fact that every one helped the

( $\alpha) \quad+$

situation

The hypotactic form which expresses the meaning of alternation is if... not (i.e. if not a then b) with the dependent clause typically coming first. For example:

a. If you win tonight, you are not likely to see me again

( $\quad+$

b. If they considered me guilty, they must prove the evidence

The sentences above mean "either they considered me guilty" or "they must prove the evidence". Either clause can be construed as the positive or negative condition; we could just as well as say "if they can't 
prove the evidence then they can't consider me guilty". However, the only difference being which one is chosen as theme.

Meanwhile the non-finite form of hypotactic intends the meaning of the primary clause. The non-finite clause is often introduced by such prepositions as besides, instead of, without, apart from and other than, and it is usually expressed in -ing clause. For example:

a. Besides spending a week in Medan, she searched for a prospect for her

$(\alpha)$

$+$

business

b. I lay down and went to sleep instead of revising my notes for the exam

$(\alpha) \quad+$

c. The boy took the money without asking whose the posses

$(\alpha)$

$+$

d. Apart from attracting business, it will undertake research and

$(\alpha) \quad+$

development for the two companies

e. You won't get ride of it, other than giving it a way
$(\alpha)$
$+$

Without a conjunctive preposition, the form is the same as that of the elaborating non-finite -ing clauses. Since non-finite dependent clauses are by nature less explicit than finite ones.

\section{Enhancement}

In enhancement, one clause enhances the meaning of another clause by qualifying it in one of a number of the following ways: by reference to time, place, manner, cause or condition (Bloor, T \& Bloor, M, 1994). The combination of enhancement with hypotaxis is realized by traditional 
grammar adverbial clause of time, place, condition, purpose, concession, reason and manner of traditional grammar. They may be finite or non-finite. Enhancement is marked through an " $\mathrm{X}$ " sign.

The markers of non-finite and finite hypotactic enhancement are summarized in the following table as adopted from Halliday (1994: 237)

\section{Table I}

Principal Markers of Hypotactic Enhancement

\begin{tabular}{|c|c|c|c|}
\hline \multirow{2}{*}{ Category } & Finite & Non-finite & \multirow{2}{*}{ Preposition } \\
\hline & Conjunction & Conjunction & \\
\hline $\begin{array}{l}\text { 1. Temporal } \\
\text { - Same time: } \\
\text { - extent } \\
\text { - point } \\
\text { - spread } \\
\text { - Different time: } \\
\text { - later } \\
\text { - earlier }\end{array}$ & $\begin{array}{l}\text { As, while } \\
\text { When, as } \\
\text { soon as, the } \\
\text { moment } \\
\text { Whenever, } \\
\text { every time } \\
\text { After, since } \\
\text { Before, until/ } \\
\text { till }\end{array}$ & $\begin{array}{l}\text { While } \\
\text { When }\end{array}$ & $\begin{array}{l}\text { In (the course/ } \\
\text { process of) } \\
\text { On } \\
\text { After } \\
\text { Before }\end{array}$ \\
\hline $\begin{array}{ll}\text { 2. } & \text { Spatial } \\
\text { - } & \text { Same place: } \\
\text { - } & \text { extent } \\
\text { - } & \text { point } \\
\text { - } & \text { spread }\end{array}$ & $\begin{array}{l}\text { As far as } \\
\text { Where } \\
\text { Wherever, } \\
\text { everywhere }\end{array}$ & & \\
\hline $\begin{array}{l}\text { 3. Manner } \\
\text { - means } \\
\text { - comparison }\end{array}$ & $\begin{array}{l}\text { As, as if, like, } \\
\text { the way }\end{array}$ & like & By (means of) \\
\hline
\end{tabular}




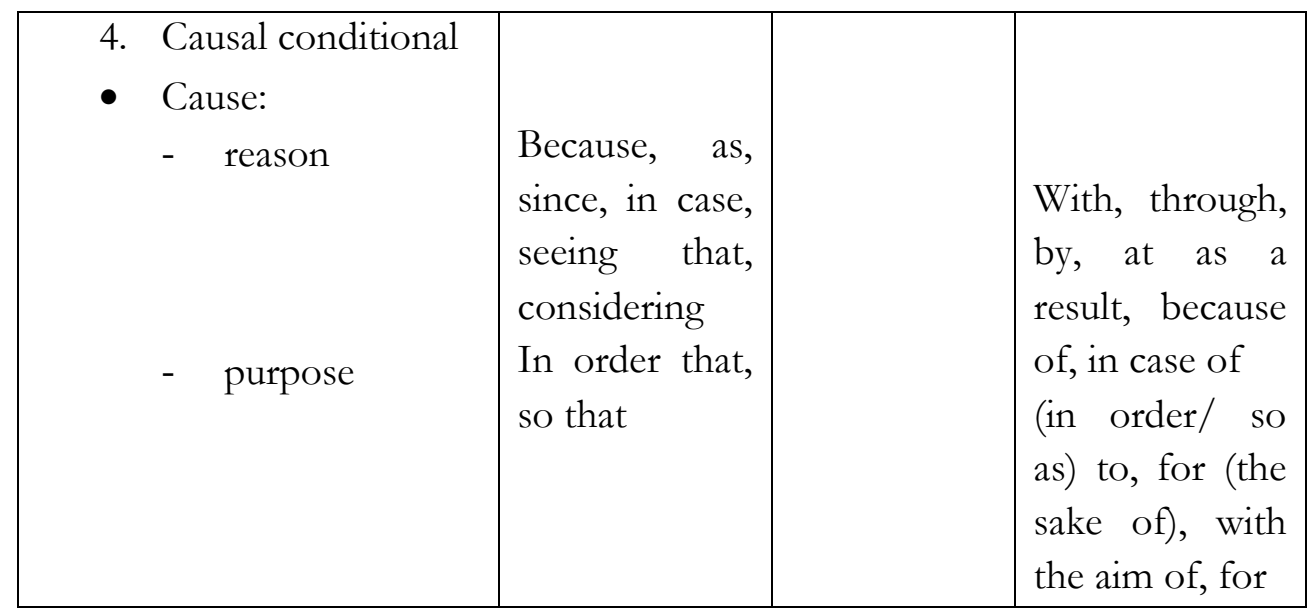

The finite ones are introduced by subordinating conjunctions which serve to indicate the dependent status of the clause together with its circumstantial relationship. As well as simple conjunctions such as because, when, if, and conjunction groups like as if, even if, soon after and so that. There are three types of complex conjunction, one derived from verbs, one from nouns and the third from adverbs as we can see on the following examples:

a. Because he was sick, he was absent

$$
(\beta)+(\alpha)
$$

b. When he took bath, the lamp went out

$$
\text { ( } \beta)+(\alpha)
$$

c. He talks about it as if it was a game

$$
(\beta)+(\alpha)
$$

While non-finite dependent clauses of enhancement express many of the meanings conveyed by the finite type in addition to some others, the semantic relationships may be made clear by means of a conjunction or a conjunctive preposition, or they may be left inexplicit as shown in these examples:

a. Don't forget to turn the light off when you leave the room 
$(\alpha)$

$$
+
$$

b. Watch out for pickpocket if traveling abroad

$(\alpha)+(\beta)$

c. Without having been there, I know all that happened

$(\beta)+(\alpha)$

If the dependent clause is non-finite, the circumstantial relationship is made explicit by the conjunction or conjunctive preposition. However, the conjunctions are a subset of those occurring in finite clauses, and their meaning is essentially the same.

\section{Projection}

Projection refers to a representation of linguistic experience in another linguistic experience. The clause I'll finish the job is a linguistic experience in the clause complex he said, "I'll finish the job", the linguistic experience is represented again in another linguistic experience of he said. Projection is the relationship which exists between a clause containing a verb of saying or thinking and a clause which expresses what is said or thought (Downing \& Locke, 1992). Hypotactic projection is one where linguistic experience is project as meaning the result is reported speech or thought. Traditionally, this is known as 'indirect speech', to indicate the meaning (idea) projected, a single quotation mark (') is used, while to indicate the wording (locution) projected, a double mark (") is used.

A projection consists of two parts the projecting (clause), and a projecting is marked by the projecting process, which is said. However, projection occurs through mental and verbal processes. Therefore, with reference to the projecting process, projection divided into locution and idea (figure of types of projection) 


\section{Locution}

A locution is projection with verbal process. With reference to Halliday (1994) verbal process used as the projecting processes may be seen from the following table:

\begin{tabular}{|c|c|}
\hline Quoted directives & Reported directives \\
\hline 1. The general process & 1. The general verb (say) \\
\hline 2. Verbs specific to offers & $\begin{array}{l}\text { 2. Statements tell }+ \text { receiver, } \\
\text { remark, observe, point out, } \\
\text { report, announce etc. } \\
\text { Question ask, demand, inquiry } \\
\text { and quiry }\end{array}$ \\
\hline $\begin{array}{l}\text { 3. Verbs embodying some } \\
\text { circumstantial or other } \\
\text { semantic feature }\end{array}$ & $\begin{array}{l}\text { 3. Reply, explain, protest, } \\
\text { continue, interrupt and warn }\end{array}$ \\
\hline $\begin{array}{l}\text { 4. Verbs with connotative } \\
\text { meaning }\end{array}$ & $\begin{array}{l}\text { 4. Insist, complain, cry, } \\
\text { boat, murmur, stammer }\end{array}$ \\
\hline
\end{tabular}

Reported speech is characterized by a series of formal features which distinguish it from quoted speech. For example:

a. Tom said that he had been there

$$
\alpha \text { “ } \beta
$$

b. Nick asked if the girl was in that room

$$
\alpha \text { " } \beta
$$

The clause containing the sayer and the reporting verb is the dominant clause and the reported element is the dependent clause. The above examples break down into two clauses: the dominant clauses Tom said 
and Nick asked and the dependent clauses that he had been there and if the girl was in that room. However, they have the effect of shifting all deictic elements away from direct reference to the speech situation, the shifts involved are:

a) First person pronouns, which refer to the speaker, are shifted to the third. The second person pronoun which refers to the listener, is shifted to the first or the third, according to the identity of the listener

b) Demonstrative and deictic adverbs which refer to (these, this, here, now) are replaced by more remote forms that, those, there, then.

c) Verb tenses are back-shifted, that is present forms are replaced by past form.

d) An interrogative in quoted speech is replaced by a declarative in reported speech.

In hypotactic locution, what someone thought or said is repackaged into an indirect form. This is the indirect speech of traditional grammar, but most also include indirect thought. A similar range of verbs is used to project hypotactically, but the projected clause (s) will be marked for dependency on the alpha projecting clause (usually by that or WH-words), ad changes to the tense and mood must be made. For example:

a. Sonia asked whether they really had to eat it

$\alpha$

$\beta$

b. She told me to give you the following instructions

$\alpha$ $\beta$

From the above report, the mood choices of the original which were most probably interrogative and imperative have not been reproduced unlike 
the original speakers. The reporter is not asking or ordering, but stating, and the mood choices is therefore declarative. Similarly, in the finite clauses in the first example the tense choices are made in relation to the context of the report, not of the original speech event.

\section{Idea}

Verbs which represent mental process are used to report ideas, beliefs, fears and speculations. Mental process used to project a linguistic experience include think, imply wonder, reflect, want, which, suspect etc. the combination of mental process with a dependent 'reporting' clause is the normal way of representing what people say, think and believe. For examples:

a. I wish (that) he would stop telling those awful jokes

$$
\alpha, \beta
$$

b. She does not want people to come in and out all day

$$
\alpha
$$

c. He thought he would finish the job

$$
\alpha, \beta
$$

d. I wondered if he meant to pick him up or pick him off

$$
\alpha, \beta
$$

In the case the ideas, there is normally no actual stretch of language to represent-certainly none in the outside world, since the thinking went on inside someone's mind. However, the link between thought and language is inherently so strong for us that the same relation of projection is used whether or not the thought was in fact formulated partly or wholly in words, the way we can talk about it in terms of language. Since there is no original wording, the norm for projecting thoughts is by means of reports, but in narratives especially, quotes can also be used. 
In other cases, however it is at least likely and at most certain that no original wording exists. Nevertheless, the expressions choices open to us still construe the mental act of meaning in terms of projection, i.e. in terms of a language phenomenon. For example:

a. You'd think there would be a warning

$$
\alpha \quad, \quad \beta
$$

b. I secretly and guiltily believed him to be right

$$
\alpha
$$

\section{CONCLUSION}

Having analyzed the topic given in this study, it can be concluded that there are various methods of combining clauses together in English by means of the clause complex. Clause complex relationships are of two kinds parataxis and hypotaxis. However, this thesis analyzes only hypotaxis.

Hypotactic relationships involving a dependency relation are labeled according to their hierarchical relationships of dependency. Greek alphabetic symbols $-\alpha, \beta, \gamma, \delta, \varepsilon-$ are conventionally used to show 'decsending' dependency. Thus, $\beta$ is dependent on $\alpha$, while $\alpha$ marks the dominant clause. Nevertheless, it is important to note that it is possible to the position of the secondary clause of a hypotactic structure precede the primary clause. Clause complexes may involve expansion and projection. Basically, there are three types of expanding; they are elaboration, extension and enhancement with the sign themselves. Furthermore, hypotactic structure can be finite or nonfinite form.

\section{REFERENCE}

Bloor, T. (1995). The Functional Analysis of English. New York: Arnold. 
Downing, A. (1992). A University Course in English Grammar. New York: Prentice Hall.

Eggins, S. (1994). An Introduction to Systemic Functional Linguistic. London: Printers.

Gerot, L. (1994). Making Sense of Functional Grammar. Sidney: Stabler Ltd.

Halliday, M. (1994).An Introducing to Functional Grammar. London: Edward Arnold.

Morley, G. D. (2000). Syntax in Functional Grammar. London: Continuum.

Siewerska, A. (1991). Functional Grammar. New York: Routledge.

Suhadi, J. e. (2001). Jurnal Linguistike Sastra. Medan: Fakultas Sastra UISU.

Suhadi, J. e. (2005). Jurnal Linguistike Sastra. Medan: Fakultas Sastra UISU.

Thompson, G. (1996). An Introduction to Functional Grammar. Tokyo: Arnold Ltd. 